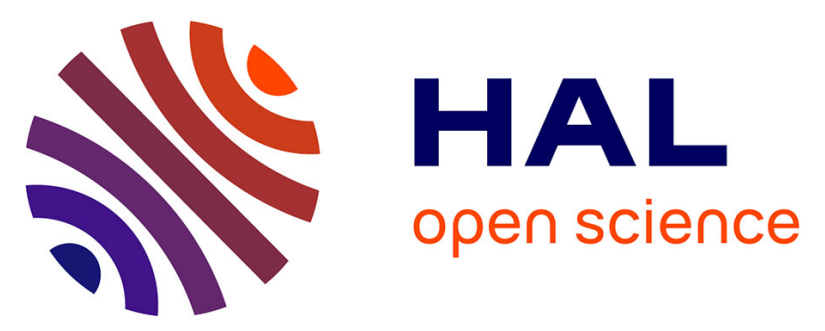

\title{
Assessing the experience of the quality of care of patients living with multiple sclerosis and their caregivers: the MusiCare Questionnaire
}

David Veillard, Karine Baumstarck, Gilles Edan, Marc Debouverie, Sandrine Wiertlewski, Jérôme de Sèze, Pierre Clavelou, Jean Pelletier, Christophe Verny, Karine Chauvin, et al.

\section{To cite this version:}

David Veillard, Karine Baumstarck, Gilles Edan, Marc Debouverie, Sandrine Wiertlewski, et al.. Assessing the experience of the quality of care of patients living with multiple sclerosis and their caregivers: the MusiCare Questionnaire. European Journal of Neurology, 2021, 28 (3), pp.910-920. 10.1111/ene.14685 . hal-03101922

\section{HAL Id: hal-03101922 \\ https://hal.science/hal-03101922}

Submitted on 25 Jan 2021

HAL is a multi-disciplinary open access archive for the deposit and dissemination of scientific research documents, whether they are published or not. The documents may come from teaching and research institutions in France or abroad, or from public or private research centers.
L'archive ouverte pluridisciplinaire HAL, est destinée au dépôt et à la diffusion de documents scientifiques de niveau recherche, publiés ou non, émanant des établissements d'enseignement et de recherche français ou étrangers, des laboratoires publics ou privés. 
Title: Assessing the experience of the quality of care of patients living with multiple sclerosis and their caregivers: the MusiCare Questionnaire

Authors: David Veillard ${ }^{1}$, Karine Baumstarck², Gilles Edan ${ }^{3}$, Marc Debouverie ${ }^{4}$, Sandrine Wiertlewski ${ }^{5}$, Jérôme De Sèze ${ }^{6}$, Pierre Clavelou ${ }^{7}$, Jean Pelletier ${ }^{8}$, Christophe Verny ${ }^{9}$, Karine Chauvin ${ }^{1}$, Marie Elisabeth Cosson $^{1}$, Anderson Loundou ${ }^{2}$, and Pascal Auquier ${ }^{2}$

\section{Affiliations}

${ }^{1}$ Public Health and Epidemiology Department, Rennes University Hospital, Rennes, France; ${ }^{2}$ Public Health:

Quality of Life and Chronic Diseases EA3279, Aix-Marseille University, Marseille, France; ${ }^{3}$ Clinical Neuroscience Centre, CIC-P 1414 INSERM, Rennes University Hospital, Rennes, France ; ${ }^{4} \mathrm{CIC}$-EC Inserm CIC 1433, Nancy University Hospital, Nancy, France; ${ }^{5}$ Neurology Department, Nantes University Hospital, Nantes, France; ${ }^{6}$ Neurology Department, Strasbourg University Hospital, Strasbourg, France; ${ }^{7}$ Neurology Department, Clermont-Ferrand University Hospital, Clermont-Ferrand, France; ${ }^{8}$ Neurology Department, Marseille University Hospital AP- HM, Marseille, France; ${ }^{9}$ Neurology Department, Angers University Hospital, Angers, France.

Corresponding author Email: David.Veillard@chu-rennes.fr

\section{Manuscript word count: 4674}

Short title: Experience of MS patients and caregivers assessed by MusiCare

Keywords: multiple sclerosis, quality of care, patient experience, validation, caregiver experience

Disclosure of Conflict of Interest: Dr. VEILLARD reports grants from the French Health Ministry, Fondation de France, and ARSEP. The other authors have nothing to disclose. 
DR. DAVID VEILLARD (Orcid ID : 0000-0003-4818-0875)

Article type : Original Article

Title: Assessing the experience of the quality of care of patients living with multiple sclerosis and their caregivers: the MusiCare Questionnaire

Authors: David Veillard ${ }^{1}$, Karine Baumstarck ${ }^{2}$, Gilles Edan ${ }^{3}$, Marc Debouverie ${ }^{4}$, Sandrine Wiertlewski ${ }^{5}$, Jérôme De Sèze ${ }^{6}$, Pierre Clavelou ${ }^{7}$, Jean Pelletier ${ }^{8}$, Christophe Verny ${ }^{9}$, Karine Chauvin ${ }^{1}$, Marie Elisabeth Cosson ${ }^{1}$, Anderson Loundou' ${ }^{2}$, and Pascal Auquier ${ }^{2}$

\section{Affiliations}

${ }^{1}$ Public Health and Epidemiology Department, Rennes University Hospital, Rennes, France; ${ }^{2}$ Public Health: Quality of Life and Chronic Diseases EA3279, Aix-Marseille University, Marseille, France; ${ }^{3}$ Clinical Neuroscience Centre, CIC-P 1414 INSERM, Rennes University Hospital, Rennes, France ; ${ }^{4} \mathrm{CIC}$ EC Inserm CIC 1433, Nancy University Hospital, Nancy, France; ${ }^{5}$ Neurology Department, Nantes University Hospital, Nantes, France; ${ }^{6}$ Neurology Department, Strasbourg University Hospital, Strasbourg, France; ${ }^{7}$ Neurology Department, Clermont-Ferrand University Hospital, ClermontFerrand, France; ${ }^{8}$ Neurology Department, Marseille University Hospital AP- HM, Marseille, France; ${ }^{9}$ Neurology Department, Angers University Hospital, Angers, France.

Corresponding author Email: David.Veillard@chu-rennes.fr

Manuscript word count: 4674

Short title: Experience of MS patients and caregivers assessed by MusiCare

Keywords: multiple sclerosis, quality of care, patient experience, validation, caregiver experience

Disclosure of Conflict of Interest: Dr. VEILLARD reports grants from the French Health Ministry, Fondation de France, and ARSEP. The other authors have nothing to disclose. 


\section{Abstract}

\section{Background}

Patients with a chronic illness, such as multiple sclerosis (MS), and their natural caregivers have a specific experience of healthcare and health services. These experiences need to be assessed to evaluate the quality of care.

\section{Objective}

Develop a French-language questionnaire to evaluate the quality of care as experienced by MS patients and their natural caregivers.

\section{Methods}

Eligible patients had been diagnosed with MS according to the McDonald criteria. Eligible caregivers were individuals designated by the patients. The MusiCare questionnaire was developed in two standard phases: 1) item generation, based on interviews with patients and caregivers, and 2) validation, consisting of validity, reliability, external validity, reproducibility, and responsiveness measures.

\section{Results}

In total, 1,088 patients $(n=660)$ and caregivers $(n=488)$ were recruited. The initial 64-item version of MusiCare was administered to a random subsample $(n=748)$. The validation process generated a 35-item questionnaire. Internal consistency and scalability were satisfactory. Testing of the external validity revealed expected associations between MusiCare scores and sociodemographic and clinical data. The questionnaire showed good reproducibility and responsiveness.

\section{Conclusion}

The availability of a reliable and validated French-language self-report questionnaire probing the experience of the quality of care for MS will allow the feedback of patients and caregivers to be incorporated into a continuous healthcare quality-improvement strategy. 


\section{Introduction}

Evaluating the quality of care for patients with multiple sclerosis (MS) is a major challenge. Patient-reported experience measures have gained increasing attention over the past 30 years, as they make an important contribution to the assessment and improvement of healthcare quality for ill populations $s^{1,2}$. Patients with chronic illness and their relatives have extensive and specific experience with healthcare and the health service. These unique experiences must be considered alongside other forms of quality-of-care assessment ${ }^{3}$. This patient-centred approach initially involved the use of satisfaction surveys, mainly during hospital stays ${ }^{4}$. However, apart from questions focusing on the reliability and validity of existing tools, the impact of survey findings on healthcare quality in hospitals has remained modest, irrespective of the country concerned ${ }^{5,6}$. Thus, research has focused on assessing the patient experience of healthcare ${ }^{7,8,9}$. Several studies have shown an association between assessment of the patient experience and improvements in the quality of provided healthcare ${ }^{10}$. Tools have been developed to assess the experience of healthcare management by patients with chronic diseases ${ }^{11}$. However, authors recommend developing tools that are adapted to particular diseases and healthcare systems ${ }^{12}$. The free choice of healthcare, universal healthcare insurance, and the existence of both private and public hospitals are specific to European countries and lead to differences in patient experiences ${ }^{13}$. No tool is currently available to evaluate the experience of patients living with MS throughout all the stages of the disease ${ }^{14}$. Furthermore, given the consequences of MS, natural caregivers should also be involved in this process ${ }^{15}$. We thus aimed to develop a French-language self-report questionnaire to assess the experience of both patients and caregivers of quality of care in MS, in accordance with psychometric standards.

\section{Methods}

The project received approval from the ethical committee of the CPP de Rennes Ouest V on November 9, 2010 ( $\mathrm{N}^{\circ}$ 10/36-778) and has been registered on clinical trials.gov (NCT02388334).

\section{Procedure}

The questionnaire was developed in two phases between 2015 and 2018: item generation (Phase 1 ) and validation (Phase 2$)^{16}$. Each phase was supervised by a steering committee 
consisting of neurologists, rehabilitation specialists, psychologists, epidemiologists, and public-health experts.

\section{Patients}

The eligibility criteria for enrolled patients were to be 1) aged 18 years or older, 2) diagnosed with any form of definitive MS according to the McDonald criteria, excluding clinically isolated syndrome, and 3) fluent in the French language. For caregivers, the criteria were to be 1 ) aged 18 years or older, 2) designated by the patient as a natural caregiver (i.e. noninstitutional relative/person most closely involved in the decisions linked to the disease), 3) fluent in the French language, and 4) free from MS. All patients and caregivers gave their written informed consent.

\section{Questionnaire development}

\section{Item generation}

Face-to-face semi structured interviews ( 25 patients and 72 caregivers) and focus groups (34 patients) to define the various domains related to the concept of the experience of MS care management were conducted between March 2015 and May 2016 by two trained interviewers/moderators (KC and MEC). The participants were recorded. Eligible patients and their caregivers, identified according to sex and MS subtype, were recruited via integrated MS healthcare networks in five regions (Alsace, Auvergne, Bretagne, ProvenceAlpes-Côte d'Azur, Pays de Loire) of France. After participants had given their consent, they attended an interview in a nonmedical venue (generally the offices of patient organizations). These interviews served to determine the wording of the items and the range of response options. They continued until no more new ideas emerged ${ }^{16}$. The content of the questionnaire was derived from a textual analysis of all the interviews, combining manual and computerized approaches (Alceste software). All the details of the qualitative study are provided in the supplementary files. Two versions of a first set of 76 items were built from themes and subthemes found to be common to patients and caregivers. These items questioned patients about their personal experience of care management and caregivers about their personal experience of the patients' care management. Items were rated on a four-point Likert scale worded in two different ways: Totally agree / Better than expected; Rather agree / As expected; Rather disagree / A little less than expected; Totally disagree / Really less than expected. A fifth response was possible: Not applicable. We chose a 12- 
month timeframe, given the progression profile of the disease and the mean number of patient contacts with healthcare professionals in the context of care in MS. In total, 14 patients and 15 caregivers underwent a cognitive debriefing. They were asked to comment on any aspects of the questionnaire (i.e., content, wording, or response choices) they felt were irrelevant or could be improved. Items that were ambiguous, misunderstood, or rarely answered were removed or reworded, leading to a 64-item version.

\section{Validation of MusiCare}

The recruitment of patients and caregivers for the validation phase took place i) during MSdedicated events organized by the regional integrated MS healthcare networks or by MS patient organizations, ii) through advertising, using the patient mailing lists of MS regional networks, or iii) through advertisements placed in consulting neurologists' offices. After consenting to participate, they received the questionnaire either though a link for online completion or by mail. Participants were included from July 5, 2017 to November 9, 2018. In addition to responses to the MusiCare questionnaire, the following data were collected: sociodemographic data, clinical data, quality of life, coping strategies, and level of disability $^{17,18,19}$. Experiences of MS, fatigue, depression, and anxiety (i) since the beginning of the disease and (ii) at the current time were rated using visual analogue scales.

\section{Final structure}

We randomly selected two thirds $(n=748)$ of the whole sample $(N=1088)$, respecting the patient-caregiver ratio. The item-reduction process was based on the results of statistical analyses and the expertise of the steering committee. Descriptive statistics were calculated to examine the distribution of responses for each item. Items with the following characteristics were removed: high rate of missing data and/or not applicable $(<25 \%)$, low index of discrimination $(<0.70)$, and high interitem correlation $(>0.80)$. Items were also deleted after examination of the item structure of the questionnaire using principal component analysis and Cronbach's alpha coefficient. Construct validity (factorial structure) was assessed with a random subsample, using principal component factor analysis with varimax rotation to determine the final structure and number of independent dimensions. A final five-factor structure with 35 items was chosen.

Stability of the final structure 
The stability of the five-factor structure was assessed on the patient subsample $(n=660)$, the caregiver subsample $(n=428)$, and the whole sample $(N=1,088)$.

\section{Psychometric testing}

Internal consistency and external validity were calculated for the random subsample of 748 individuals and the whole sample of 1,088 individuals.

\section{Reproducibility and responsiveness}

Reproducibility (ability to produce the same results in the absence of a meaningful change) and responsiveness (ability to detect a meaningful change) were assessed. To test reproducibility, 35 randomly-chosen patients and 35 randomly-chosen caregivers received a second assessment 4 weeks \pm 7 days after the first assessment (to minimize the likelihood of changes in the patients' clinical status, while allowing sufficient time to elapse between the test and retest to prevent patients from recalling their answers). Patients, as well as their caregivers, were excluded if they experienced a change in health status related to MS between the two assessments. The reproducibility analysis was finally performed for 31 patients and 15 caregivers. To test responsiveness, we performed a second assessment of 100 randomly-chosen patients $6 \pm 1$ months after the first assessment (to maximize the likelihood of changes in the patients' clinical status). Among the 88 patients who returned their questionnaire, two groups were identified: those without a change in health status and those with a change in health status. A change in health status since the first assessment was defined as a new relapse, initiation or ending of disease-modifying drugs, or disability progression (evolution to a secondary progressive form).

\section{Statistical analysis}

Validation of the MusiCare questionnaire included construct validity, reliability, external validity, reproducibility, and responsiveness. Construct validity was assessed using principal component factor analysis with varimax rotation ${ }^{16}$. Eigenvalues $\geq 1$ were retained. Items were included in the dimensions if they had loadings $>0.4$. If an item loaded on several factors, it was included in the factor that had the closest conceptual relationship. Confirmatory factor analysis was performed using the LISREL model. The following indicators were required: the root mean square error of approximation (RMSEA) was considered acceptable if $<0.08$ and the comparative fit index (CFI) if $>0.9$. Internal 
consistency of the items was assessed by correlating each item with its dimension (corrected for overlap) using Pearson's correlation coefficient $(r=0.4)$, recommended for testing item internal consistency ${ }^{20}$. The validity of the discriminative capacity of the items was assessed by determining the extent to which items correlated more highly with the dimensions they were hypothesized to represent than with the others ${ }^{21}$. For each dimension, the reliability of internal consistency was assessed using McDonald's omega coefficient (coefficient $\geq 0.7$ expected for each scale. The uni-dimensionality of each dimension was assessed by Rasch analysis. The goodness-of-fit statistics (INFIT, ranging between 0.7 and 1.3) ensured that all items of the scale measured the same concept. We found floor and ceiling effects when we assessed the homogeneous distribution of responses. Inter-dimension correlations were examined using Pearson's $r$ and polychoric correlations.

To explore external validity, relationships between the following dimensions were assessed using Pearson's $r$ : dimensions of MusiCare and experience of MS, fatigue, depression, and anxiety ratings and disability and quality of life scores. The validity of the discriminative capacity was determined by assessing the associations between the MusiCare scores and sociodemographic and clinical features (sex, marital status, education level, MS subtype, MS treatment, age, and duration of the disease).

Reproducibility was tested by assessing test-retest reliability using intraclass correlation coefficients (ICC) between the two successive assessments in stable individuals (i.e. no health changes in patients); a minimum of 25 observations was necessary to detect ICCs > 0.85 (90\% confidence interval with a width of 0.20$)$. Responsiveness was measured in terms of effect size (ES, i.e. mean change in MusiCare scores between the first and second assessments divided by the standard deviation of the baseline score); a minimum of 90 observations allows detection of a minimal effect size of 0.30 (significance level at 0.05 using a two-sided paired t-test). An ES of $0.2,0.5$, and 0.8 were considered to be small, moderate, and large, respectively ${ }^{22}$.

Data analyses were performed using SPSS 20.0, MAP-R, and WINSTEP software. 


\section{Results}

Only the results of the final psychometric validation phase of the MusiCare questionnaire are reported here.

\section{Sample characteristics}

Among the 1,379 individuals (830 patients and 549 caregivers) who provided their contact details, 660 patients with MS (79.5\%) and 428 caregivers (77.9\%) were included. Nonparticipants did not differ significantly from participants for either sex or duration of the disease.

\section{Scoring}

For each individual, we calculated dimension scores if they had responded to at least half of the contributing items. All dimension scores were linearly transformed and standardized using a scale ranging from 0 (lowest experience) to 100 (highest experience).

\section{Validity}

The total sample for the validation phase consisted of 1,036 participants (95.2\%), excluding participants whose questionnaires had more than $30 \%$ missing data, in accordance with the steering committee's decision. The characteristics of the patients and caregivers in the study sample are presented in Table 1.

\section{Construct validity and internal structural validity}

We discarded 29 of the 64 initial items on account of at least one of the following situations: low response rate, low discrimination index, and high interitem correlation. Based on the random subsample of 748 observations, the 35-item structure of the MusiCare was confirmed by principal component factor analysis, which identified a five-factor structure accounting for $63 \%$ of the total variance. This model showed a good fit and all the indices yielded by the confirmatory LISREL model were satisfactory (RMSEA $=0.091 ; 90 \% \mathrm{Cl}[0.089$, 0.094], CFI = 0.944). The stability of the five-factor structure was tested on the patient subsample, the caregiver subsample, and the whole sample. The dimensions were named according to their contributing items: information about the disease (11 items), information about treatments/medical investigations (8), relationships with healthcare teams (8), healthcare access (5), and reception conditions in care centres (4). The structures are 
described in supplementary Table 1. The 35 items are detailed in supplementary Table 2. Internal consistency was satisfactory for all dimensions for both the random subsample and the whole sample. Each item achieved the 0.40 standard for item internal consistency, except for one healthcare access domain. The correlation of each contributing item with its dimension was higher than its correlations with the other dimensions (item discriminant validity), except for healthcare access. McDonald's omega coefficients ranged from 0.71 to 0.93, indicating satisfactory internal consistency. Overall scalability was satisfactory: few items showed an infit statistic outside the acceptable range. The characteristics of the item and dimension scales (random subsample and whole sample) of MusiCare are summarized in Table 2. Inter-dimension correlation coefficients ranged from 0.28 to 0.70 (all $p<0.001$ ). The scores of patients and caregivers are presented in Figure 1.

\section{External validity}

As expected, the MusiCare scores for both patients and caregivers correlated with the ratings of experience of fatigue, mood disorders, anxiety status, disability, quality of life, and caregiver burden. The details are provided in Table 3.

For the patients, there were no statistical associations between experience of MS care and sex or MS subtype. Older patients reported a more positive experience than younger patients for some dimensions. For the caregivers, men reported a more positive experience than women, as did caregivers who stated that they were not the sole caregiver. Being in a couple and having a higher education level were associated with a better experience for several dimensions, both for patients and caregivers. Details are provided in Table 4.

\section{Reproducibility and responsiveness}

Reproducibility was satisfactory for both patients $(n=31)$ and caregivers $(n=15)$, with ICCS ranging from 0.60 to 0.98 . Concerning responsiveness, among the patients whose health status deteriorated $(n=12)$, the ES ranged from -0.36 to -0.55 , except for the relationships with healthcare teams $(-0.06)$. All the ESs were low for stable patients $(n=62)$ and higher for patients with a worsening health status $(n=12)$. The details are reported in Table 5. 


\section{Discussion}

MusiCare is the first validated tool to have been designed specifically to assess the quality of MS care as perceived by patients and their caregivers. Patient and caregiver experience assessments are used to improve care management, compare services, facilitate choices to provide appropriate strategies, and evaluate the impact of implementing these strategies ${ }^{23}$. The results of the development and validation phases reported here show that the MusiCare questionnaire is also such an instrument.

Identifying the components of the questionnaire, based on face-to-face interviews conducted with patients and caregivers, reinforced the validity of its content. This procedure ensured that the components of the experience of the quality of MS care management were identified based on relevant information provided by the individuals themselves ${ }^{24}$.

MusiCare met all necessary psychometric standards. Its internal structure, supported by high internal consistency, confirmed that the experience of MS care quality is a multidimensional concept. A number of general instruments evaluating patient experience have been published over the past 15 years ${ }^{25,26}$. Most have measured patients' experience of healthcare provided in hospitals, even though most of the care for patients with MS is carried out on an outpatient basis ${ }^{27}$. The Patient Assessment of Chronic Illness Care was developed to measure patient experience in the context of the chronic-care model in the United States but does not involve caregivers ${ }^{22}$. The only tool for caregivers is the measure of the experience of family caregivers looking after elderly patients with a high degree of dependency of Guilabert et al. ${ }^{28}$

According to these instruments, the quality of information and communication between patients and healthcare professionals are the two most highly developed dimensions in terms of care and its organization, as well as in terms of treatments and medical investigations. MusiCare also emphasizes the need for information and communication between patients, their caregivers, and healthcare providers, as previously observed in French questionnaires probing satisfaction with hospital care ${ }^{29}$. Two other dimensions addressed by most of these instruments are confidence, support, and access to care, also included in MusiCare. 
Our choice of a Likert scale with an even number of options was based on previous reports demonstrating that it is more informative and discriminative than either a yes/no form or an odd scale.

Reproducibility and responsiveness, core psychometric properties of any measuring instrument, are rarely reported, as longitudinal data collection is required ${ }^{30}$. For patients, we were able to measure both of these aspects, showing satisfactory stability of MusiCare in the absence of a meaningful change in health status, and a satisfactory ability to detect a meaningful change in health status. For caregivers, we can only provide information about reproducibility based on a small number of individuals and have no information about responsiveness. More studies are therefore needed to complete this initial investigation, although the present findings demonstrate the relevance of the tool.

External validity, explored as a function of sociodemographic, clinical, and psychobehavioural characteristics, generally confirmed our assumptions. The relationship with EDSS is lacking and should be explored in the future. As expected, fatigue, emotional status, and disability negatively influenced the experience of care quality. This information will allow specific actions to be targeted and implemented to improve patient management. Caregivers' perceived burden was also associated with a poorer experience of care quality. This finding should confirm the need to pay more attention to caregivers as key actors in the provision of healthcare and key contributors to patients' adherence to and acceptance of treatment ${ }^{31,32}$. Experience of care quality positively correlated with quality of life, confirming the importance of considering this factor when evaluating disease progression, treatment, and the management of care provided to patients with $\mathrm{MS}^{33}$.

Our approach also had several limitations. First, fixed-length instruments have several drawbacks. The reduction in questions carries a risk of losing relevant information, potentially resulting in reduced measurement precision. Among the items in the initial set, some were clearly relevant to the experience of the quality of care. New approaches should be developed to avoid losing such information based on computerized adaptive testing ${ }^{34}$. This method proposes items drawn from an item bank that can collect the most information about a given individual, improving both precision and reducing the time necessary to complete the questionnaire ${ }^{35}$. Participation in the item generation and validation phases 
was purely voluntary. It is thus possible that individuals living in isolation or those who are reluctant to seek help from the healthcare system did not take part. As a result, certain aspects that they experience may not have been considered.

\section{Conclusion}

MusiCare, a measure of perceived experience of the quality of care in MS, was generated from exclusive interviews with patients and their caregivers. The availability of a reliable and validated questionnaire will allow it to be factored into a continuous healthcare qualityimprovement strategy.

\section{Acknowledgements}

The authors thank Estelle Delepau for her contribution to the data analysis, Aurore Muret, Yoann Desilles, and Emilie Chretien for coordinating the recruitment of patients and caregivers, implemented by MS Healthcare networks and the Observatoire Français de la Sclérose en Plaques (OFSEP).

\section{Data availability statement:}

The data that support the findings of this study are available from the corresponding author upon reasonable request.

\section{References}

1. Institute of medicine: Crossing the chasm: a new health system for the 21st century. Washington DC : National Academy Press (US); 2001.

2. Carman KL, Dardess P, Maurer M, Sofaer S, Adams K, Bechtel C, Sweeney J. Patient and family engagement: a framework for understanding the elements and developing interventions and policies. Health Aff (Millwood) 2013;32:223-231.

3. Anhang Price R, Elliott MN, Zaslavsky AM, Hays RD, Lehrman WG, Rybowski L, EdgmanLevitan S, Cleary PD. Examining the role of patient experience surveys in measuring health care quality. Med Care Res Rev 2014;71:522-554.

4. Williams B, Coyle J, Healy D. The meaning of patient satisfaction: an explanation of high reported levels. Soc Sci Med 1998;47:1351-1359.

5. Crow R, Gage H, Hampson S, Hart J, Kimber A, Storey L, Thomas H. The measurement of satisfaction with healthcare: implications for practice from a systematic review of the literature. Health Technol Assess 2002;6:1-244. 
6. Bombard Y, Baker GR, Orlando E, Fancott C, Bhatia P, Casalino S, Onate K, Denis JL, Pomey MP. Engaging patients to improve quality of care: a systematic review. Implement Sci 2018;13:98.

7. Darby C, Crofton C, Clancy CM. Consumer assessment of health providers and systems (CAHPS): evolving to meet stakeholder needs. Am J Med Qual 2006;21:144-147.

8. Anhang Price R, Elliott MN, Zaslavsky AM, Hays RD, Lehrman WG, Rybowski L, EdgmanLevitan S, Cleary PD. Examining the role of patient experience surveys in measuring health carequality. Med Care Res Rev 2014;71:522-554.

9. Elwyn G, Buetow S, Hibbard J, Wensing M. Measuring quality through performance. Respecting the subjective: quality measurement from the patient's perspective. BMJ 2007; 335:1021-1022.

10. Doyle C, Lennox L, Bell D. A systematic review of evidence on the links between patient experience and clinical safety and effectiveness. BMJ Open 2013;3.

11. Mira JJ, Nuño-Solinís R, Guilabert-Mora M, Solas-Gaspar O, Fernández-Cano P, GonzálezMestre MA, Contel JC, Del Rio-Camara M. Development and Validation of an Instrument for Assessing Patient Experience of Chronic Illness Care. Int J Integr Care 2016;16:13.

12. Forestier B, Anthoine E, Reguiai Z, Fohrer C, Blanchin M. A systematic review of dimensions evaluating patient experience in chronic illness. Health Qual Life Outcomes 2019;17:19.

13. Fielding JE, Lancry PJ. Lessons from France 'vive la difference'. The French health care system and US health system reform. JAMA 1993;270:748-756.

14. Solheim AM, Mygland ̊̊, Ljøstad U. Quality of multiple sclerosis out-patient health care services with focus on patient reported experiences. BMC Res Notes 2017;10:250.

15. Rieckmann P, Boyko A, Centonze D, Elovaara I, Giovannoni G, Havrdová E, Hommes O, Kesselring J, Kobelt G, Langdon D, Lelorier J, Morrow SA, Oreja-Guevara C, Schippling S, Thalheim C, Thompson H, Vermersch P. Achieving patient engagement in multiple sclerosis: A perspective from the multiple sclerosis in the 21st Century Steering Group. Mult Scler Relat Disord 2015;4:202-218.

16. Juniper EF, Guyatt GH, Mesbah M, Ravaud P. Quality of life and pharmacoeconomics in clinical trials. Philadelphia: Lippincott-Raven; 1996.

17. Simeoni MC, Auquier P, Fernandez O, Flachenecker P, Stecchi S, Constantinescu C, Idiman E, Boyko A, Beiske AG, Vollmer T, Triantafyllou N, O'Connor P, Barak Y, Biermann L, Cristiano E, Atweh S, Patrick DI, Robitail S, Ammoury N, Beresniak A, Pelletier J, MusiQol study group. Validation of the Multiple Sclerosis International Quality of Life questionnaire. Mult Scler 2008;14:219-230. 
18. Baumstarck K, Alessandrini M, Hamidou Z, Auquier P, Leroy T, Boyer L. Assessment of coping: a new french four-factor structure of the brief COPE inventory. Health Qual Life Outcomes 2017;15:8.

19. Harwood RH, Rogers A, Dickinson E, Ebrahim S. Measuring handicap: the London Handicap Scale, a new outcome measure for chronic disease. Qual Health Care 1994;3:11-16.

20. Carey RG, Seibert JH. A patient survey system to measure quality improvement: questionnaire reliability and validity. Med Care 1993;31:834-845.

21. Campbell DT, Fiske DW. Convergent and discriminant validation by the multitraitmultimethod matrix. Psychol Bull 1959;56:81-105.

22. Cohen J. Statistical power analysis for the behavioral sciences. New York: Lawrence Erlbaum Associates; 1977.

23. Mattarozzi K, Baldin E, Zenesini C, Solari A, Amato MP, Leone M, Mancardi G, Martinelli V, Savettieri G, Solaro C, Tola MR, D'Alessandro R; Agorà Study Group. Effect of organizational features on patient satisfaction with care in Italian multiple sclerosis centres. Eur J Neurol. 2017 Apr;24(4):631-637.

24. Britten N. Qualitative interviews in medical research. BMJ 1995;311:251-253.

25. Glasgow RE, Wagner EH, Schaefer J, Mahoney LD, Reid RJ, Greene SM. Development and validation of the Patient Assessment of Chronic Illness Care (PACIC). Med Care 2005;43:43644.

26. Mira JJ, Nuño-Solinís R, Guilabert-Mora M, Solas-Gaspar O, Fernández-Cano P, GonzálezMestre MA, Contel JC, Del-Rio Camara M. Development and Validation of an Instrument for Assessing Patient Experience of Chronic Illness Care. Int J Integr Care 2016;16:13.

27. Beattie M, Murphy DJ, Atherton I, Lauder W. Instruments to measure patient experience of healthcare quality in hospitals: a systematic review. Syst Rev 2015;4:97.

28. Guilabert M, Amil P, González-Mestre A, Gil-Sánchez E, Vila A, Contel JC, Ansotegui JC, Solas O, Bacigalupe MT, Fernandez-Cano P, Arteagoitia M, Mira JJ. The Measure of the Family Caregivers' Experience. Int J Environ Res Public Health 2018;15:2040.

29. Antoniotti S, Baumstarck-Barrau K, Simeoni MC, Sapin C, Labarere J, Gerbaud L, Boyer L, Colin C, François P, Auquier P. Validation of a French hospitalized patients' satisfaction questionnaire: the QSH-45. Int J Qual Health Care 2009;21:243-252.

30. Guyatt G, Walter S, Norman G. Measuring change over time: assessing the usefulness of evaluative instruments. J Chronic Dis 1987;40:171-178.

31. Kim Y, Baker F, Spillers RL, Wellisch DK: Psychological adjustment of cancer caregivers with multiple roles. Psychooncology 2006;15:795-804. 
32. Hodges L, Humphris GM, Macfarlane G. A meta-analytic investigation of the relationship between the psychological distress of cancer patients and their carers. Soc Sci Med 2005; $60: 1-12$

33. Mitchell AJ, Benito-Leon J, Gonzalez JM, Rivera-Navarro J. Quality of life and its assessment in multiple sclerosis: integrating physical and psychological components of wellbeing. Lancet Neurol 2005;4:556-566.

34. Walker J, Bohnke JR, Cerny T, Strasser F. Development of symptom assessments utilising item response theory and computer-adaptive testing--a practical method based on a systematic review. Crit Rev Oncol Hematol 2010;73:47-67.

35. Reeve BB, Hays RD, Bjorner JB, Cook KF, Crane PK, Teresi JA, Thissen D, Revicki DA, Weiss DJ, Hambleton RK, Liu H, Gershon R, Reise SP, Lai JS, Cella D, PROMIS Cooperative Group. Psychometric evaluation and calibration of health-related quality of life item banks: plans for the Patient-Reported Outcomes Measurement Information System (PROMIS). Med Care 2007;45:S22-31. 
Table 1. Patients and caregivers characteristics

\begin{tabular}{|c|c|c|c|}
\hline & & $\begin{array}{l}\text { Patients N=660 } \\
N(\%)\end{array}$ & $\mathrm{MD}^{\circ}$ \\
\hline \multirow[t]{2}{*}{ Sex } & Women & $475(73.4)$ & $13(2.0)$ \\
\hline & Men & $172(26.6)$ & \\
\hline \multirow[t]{2}{*}{ Age (years) } & $\mathrm{M} \pm \mathrm{SD}$ & $49.3 \pm 12.1$ & \\
\hline & $\mathrm{m}[\mathrm{IQR}]$ & $50[40-58]$ & \\
\hline \multirow[t]{2}{*}{ Marital status } & Couple & $476(73.7)$ & $14(2.1)$ \\
\hline & Single & $170(26.3)$ & \\
\hline \multirow[t]{2}{*}{ Educational level } & $<12$ years & $183(28.0)$ & $7(1.1)$ \\
\hline & $>=12$ years & $470(72.0)$ & \\
\hline \multirow[t]{2}{*}{ Children } & No & $176(26.8)$ & $4(0.6)$ \\
\hline & Yes & $480(73.2)$ & \\
\hline \multirow[t]{3}{*}{ Professional status } & No-workers & $323(51.4)$ & $31(4.7)$ \\
\hline & Part time worker & $136(21.6)$ & \\
\hline & Full time worker & $170(27.0)$ & \\
\hline \multirow[t]{2}{*}{ Living place } & Personal house & $611(95.0)$ & $17(2.6)$ \\
\hline & Other place & $32(5.0)$ & \\
\hline \multirow[t]{2}{*}{ MS subtype } & Relapsing remitting & $381(65.5)$ & $78(11.8)$ \\
\hline & Progressive & $201(34.5)$ & \\
\hline \multirow[t]{2}{*}{ Disease duration (years) } & $\mathrm{M} \pm \mathrm{SD}$ & $15.5 \pm 10.3$ & \\
\hline & $\mathrm{m}[\mathrm{IQR}]$ & 14 [7-22] & \\
\hline MS treatment & No & $137(21.2)$ & $15(2.3)$ \\
\hline
\end{tabular}




\begin{tabular}{|c|c|c|c|}
\hline & Yes & $508(78.8)$ & \\
\hline Other chronic disease & & $220(34.5)$ & $22(3.3)$ \\
\hline \multirow[t]{3}{*}{ Specialized medical follow-up } & & $630(98.3)$ & $19(2.9)$ \\
\hline & & Caregivers $\mathrm{N}=428$ & \\
\hline & & N (\%) & MD \\
\hline \multirow[t]{2}{*}{ Sex } & Women & $195(46.3)$ & $7(1.6)$ \\
\hline & Men & $226(53.7)$ & \\
\hline \multirow[t]{2}{*}{ Age (years) } & $\mathrm{M} \pm \mathrm{SD}$ & $53.5 \pm 13.2$ & \\
\hline & $m[I Q R]$ & $55[46-63]$ & \\
\hline \multirow[t]{2}{*}{ Marital status } & Couple & $376(89.5)$ & $8(1.9)$ \\
\hline & Single & 44 (10.5) & \\
\hline \multirow[t]{2}{*}{ Educational level } & $<12$ years & $135(32.1)$ & $7(1.6)$ \\
\hline & $>=12$ years & $286(67.9)$ & \\
\hline \multirow[t]{2}{*}{ Children } & No & $84(20.0)$ & $8(1.9)$ \\
\hline & Yes & $336(80.0)$ & \\
\hline \multirow[t]{3}{*}{ Professional status } & No-workers & $161(39.6)$ & \\
\hline & Part time job & $37(9.1)$ & \\
\hline & Full time job & $209(51.4)$ & \\
\hline \multirow[t]{3}{*}{ Relationship with the MS patient } & Love partner & $321(77.3)$ & $13(3.0)$ \\
\hline & Parent & $73(17.6)$ & \\
\hline & Others & $21(5.1)$ & \\
\hline \multirow[t]{2}{*}{ Presence of other caregiver } & Non & $122(30.3)$ & $26(6.1)$ \\
\hline & Yes & $280(69.7)$ & \\
\hline Level of burden (from Zarit scale) & No & $192(51.3)$ & $54(12.6)$ \\
\hline
\end{tabular}




\begin{tabular}{lll} 
& Mild & $125(33.4)$ \\
& Moderate & $55(14.7)$ \\
\hline MS subtype & Severe & $2(0.5)$ \\
\hline Disease duration (years) & Relapsing remitting & $190(49.9)$ \\
& Progressive & $191(50.1)$ \\
\hline
\end{tabular}

$\mathrm{M} \pm \mathrm{SD}$, mean \pm standard deviation ; $\mathrm{m}[\mathrm{IQR}]$, median [interquartile range] ; MS multiple sclerosis ; MD missing data 
Table 2. Dimension characteristics of the self-perceived experience of multiple sclerosis care management quality questionnaire (MusiCare)

\begin{tabular}{|c|c|c|c|c|c|c|}
\hline \multicolumn{7}{|l|}{ Sub-sample $\mathbf{N}=748$} \\
\hline Dimension / index (Number of items) & Score & MV & IIC & IDV & Mac & INFIT $^{*}$ \\
\hline Self-perceived experience about... & $M \pm S D$ & $\%$ & $\min -\max$ & $\min -\max$ & Donald & $\min -\max$ \\
\hline Information about the disease (11) & $66,40 \pm 20,03$ & 15,9 & $0.60-0.77$ & $0.16-0.54$ & 0.93 & $0.8-1.6$ \\
\hline Information about the treatments/medical investigation (8) & $75,28 \pm 19,31$ & 15,1 & $0.67-0.81$ & $0.22-0.63$ & 0.92 & $0.7-1.4$ \\
\hline Relationships with health care teams (8) & $79,60 \pm 17,52$ & 12,3 & $0.54-0.80$ & $0.07-0.47$ & 0.91 & $0.7-1.7$ \\
\hline Health care access (5) & $59,12 \pm 17,25$ & 15,8 & $0.32-0.68$ & $0.18-0.47$ & 0.76 & $0.7-1.3$ \\
\hline Reception conditions in care centres ( 3 ) & $59,67 \pm 17,48$ & 22,3 & $0.54-0.55$ & $0.20-0.41$ & 0.71 & $0.9-1.1$ \\
\hline \multicolumn{7}{|l|}{ Whole sample $\mathrm{N}=1088$} \\
\hline Dimension / index (Number of items) & Score & MV & IIC & IDV & Mac & INFIT $^{*}$ \\
\hline Self-perceived experience about... & $\mathrm{M} \pm \mathrm{SD}$ & $\%$ & $\min -\max$ & $\min -\max$ & Donald & $\min -\max$ \\
\hline Information about the disease (11) & $66,03 \pm 20,09$ & 14,8 & $0.61-0.74$ & $0.20-0.57$ & 0.92 & $0.8-1.7$ \\
\hline Information about the treatments/medical investigation (8) & $75,43 \pm 19,12$ & 13,6 & $0.67-0.80$ & $0.20-0.59$ & 0.92 & $0.8-1.4$ \\
\hline Relationships with health care teams (8) & $79,68 \pm 18,01$ & 11,0 & $0.56-0.80$ & $0.12-0.48$ & 0.91 & $0.7-1.6$ \\
\hline Health care access (5) & $58,70 \pm 17,87$ & 13,9 & $0.43-0.70$ & $0.20-0.51$ & 0.79 & $0.7-1.3$ \\
\hline Reception conditions in care centres (3) & $60,10 \pm 17,36$ & 21,3 & $0.54-0.55$ & $0.19-0.39$ & 0.73 & $0.9-1.1$ \\
\hline
\end{tabular}

$\mathrm{M} \pm \mathrm{SD}$, mean \pm standard deviation ; MV, missing values ; IIC item internal consistency; IDV item discriminant validity; INFIT, Rasch statistics

All scores range from 0 (worst) to 100 (better) self-perceived care management quality 
Table 3. MusiCare scores according to psychobehavorial aspects: patients and caregivers

\begin{tabular}{|c|c|c|c|c|c|c|c|c|c|c|c|}
\hline & \multicolumn{6}{|l|}{ Patients } & \multicolumn{5}{|l|}{ Caregivers } \\
\hline & $\begin{array}{l}\text { Inform. } \\
\text { about the } \\
\text { disease }^{\circ}\end{array}$ & $\begin{array}{l}\text { Inform. } \\
\text { Treatm./med. } \\
\text { Investigation }\end{array}$ & $\begin{array}{l}\text { Relationships } \\
\text { health care } \\
\text { teams }^{\circ}\end{array}$ & $\begin{array}{l}\text { Health } \\
\text { care } \\
\text { access }^{\circ}\end{array}$ & $\begin{array}{l}\text { Reception } \\
\text { conditions in } \\
\text { care centres }^{\circ}\end{array}$ & & $\begin{array}{l}\text { Inform. } \\
\text { about the } \\
\text { disease }^{\circ}\end{array}$ & $\begin{array}{l}\text { Inform. } \\
\text { Treatm./med. } \\
\text { Investigation }^{\circ}\end{array}$ & $\begin{array}{l}\text { Relationships } \\
\text { health care } \\
\text { teams }\end{array}$ & $\begin{array}{l}\text { Health } \\
\text { care } \\
\text { access }^{\circ}\end{array}$ & $\begin{array}{l}\text { Reception } \\
\text { conditions in } \\
\text { care centres }\end{array}$ \\
\hline \multicolumn{12}{|c|}{ Self perceived exper. $(0-10)^{\sim}$} \\
\hline Globally & $0,486 * *$ & $0,405^{* *}$ & $0,393^{* *}$ & $0,348^{* *}$ & $0,287^{* *}$ & & $0,518 * *$ & $0,447 * *$ & $0,381 * *$ & $0,426 * *$ & $0,347^{* *}$ \\
\hline Actually & $0,617^{* *}$ & $0,521 * *$ & $0,518 * *$ & $0,472 * *$ & $0,293 * *$ & & $0,618 * *$ & $0,531 * *$ & $0,469 * *$ & $0,549 * *$ & $0,369 * *$ \\
\hline \multicolumn{12}{|l|}{ Fatigue $(0-10)^{+}$} \\
\hline Globally & $-0,128 * *$ & $-0,081$ & $-0,115^{* *}$ & $-0,084 *$ & $-0,098 *$ & & $-0,224 * *$ & $-0,141 * *$ & $-0,148 * *$ & $-0,072$ & $-0,051$ \\
\hline Actually & $-0,163 * *$ & $-0,094 *$ & $-0,047$ & $-0,084 *$ & $-0,068$ & & $-0,224 * *$ & $-0,132 *$ & $-0,141 * *$ & 0,013 & 0,012 \\
\hline \multicolumn{12}{|l|}{${\text { Depression }(0-10)^{+}}^{+}$} \\
\hline Globally & $-0,170 * *$ & $-0,112 * *$ & $-0,152 * *$ & $-0,137 * *$ & $-0,085^{*}$ & & $-0,250 * *$ & $-0,182 * *$ & $-0,184 * *$ & $-0,137 * *$ & $-0,114 *$ \\
\hline Actually & $-0,199 * *$ & $-0,120 * *$ & $-0,134 * *$ & $-0,140 * *$ & $-0,091^{*}$ & & $-0,219 * *$ & $-0,170 * *$ & $-0,143 * *$ & $-0,067$ & $-0,044$ \\
\hline \multicolumn{12}{|l|}{ Anxiety $(0-10)^{+}$} \\
\hline Globally & $-0,094 *$ & $-0,103^{*}$ & $-0,123 * *$ & $-0,132 * *$ & $-0,045$ & & $-0,175^{* *}$ & $-0,110 *$ & $-0,109 *$ & $-0,084$ & $-0,068$ \\
\hline Actually & $-0,153 * *$ & $-0,146 * *$ & $-0,157 * *$ & $-0,175^{* *}$ & $-0,128 * *$ & & $-0,176^{* *}$ & $-0,124 *$ & $-0,097$ & $-0,071$ & $-0,048$ \\
\hline \multicolumn{12}{|l|}{ Impact on daily living $^{\varrho}$} \\
\hline Mobility & $-0,077$ & $-0,058$ & $-0,03$ & $-0,029$ & $-0,021$ & & $-0,043$ & $-0,017$ & 0,07 & $-0,146 * *$ & $-0,039$ \\
\hline Autonomy & $-0,117^{* *}$ & $-0,063$ & $-0,008$ & $-0,041$ & $-0,136 * *$ & & $-0,108 *$ & $-0,115^{*}$ & 0,049 & $-0,117^{*}$ & $-0,087$ \\
\hline Leasures & $-0,058$ & $-0,001$ & 0,039 & $-0,023$ & $-0,033$ & & $-0,193 * *$ & $-0,129 *$ & $-0,021$ & $-0,163 * *$ & $-0,091$ \\
\hline Social relationship & $-0,122 * *$ & $-0,106 * *$ & $-0,080^{*}$ & $-0,146 * *$ & $-0,114 * *$ & & $-0,256 * *$ & $-0,239 * *$ & $-0,076$ & $-0,243 * *$ & $-0,240 * *$ \\
\hline Environment & $0,085^{*}$ & 0,007 & 0,019 & 0,027 & 0,002 & & $-0,207 * *$ & $-0,235^{* *}$ & $-0,062$ & $-0,196 * *$ & $-0,132 *$ \\
\hline Finances & $-0,047$ & 0,023 & $-0,023$ & $-0,085^{*}$ & $-0,048$ & & $-0,176^{* *}$ & $-0,157^{* *}$ & $-0,045$ & $-0,154 * *$ & $-0,114 *$ \\
\hline Quality of life MusiQoL^^ & & & & & & Burden & $-0,307^{* *}$ & $-0,271 * *$ & $-0,151^{* *}$ & $-0,276^{* *}$ & $-0,155^{* *}$ \\
\hline Activity of daily living & $0,232 * *$ & $0,146 * *$ & $0,104 *$ & $0,087^{*}$ & $0,098 *$ & & & & & & \\
\hline
\end{tabular}




$\begin{array}{llllll}\text { Psychol. well-being } & 0,269^{* *} & 0,189^{* *} & 0,180^{* *} & 0,169^{* *} & 0,165^{* *} \\ \text { Relations with friends } & 0,137^{* *} & 0,129^{* *} & 0,157^{* *} & 0,059 & 0,009 \\ \text { Symptoms } & 0,273^{* *} & 0,165^{* *} & 0,136^{* *} & 0,148^{* *} & 0,103^{*} \\ \text { Relations with family } & 0,192^{* *} & 0,181^{* *} & 0,164^{* *} & 0,159^{* *} & 0,117^{* *} \\ \text { Relations health care } & & & & & \\ \text { system } & 0,553^{* *} & 0,489^{* *} & 0,480^{* *} & 0,355^{* *} & 0,314^{* *} \\ \text { Sentim. and sexual life } & 0,180^{* *} & 0,184^{* *} & 0,141^{* *} & 0,182^{* *} & 0,068 \\ \text { Coping } & 0,165^{* *} & 0,079 & 0,171^{* *} & 0,082^{*} & 0,05 \\ \text { Rejection } & 0,211^{* *} & 0,149^{* *} & 0,127^{* *} & 0,106^{*} & 0,142^{* *}\end{array}$

${ }^{\circ}$ All scores range from 0 (worst) to 100 (better) self-perceived experience of care management quality

from 0 (worst) to 10 (better) self perceived experience for MS care

${ }^{+}$from 0 (lower) to 10 (higher) level of fatigue, mood disorder, anxiety

@ London Handicap Scale from 0 (lower) normal function to 1 (higher) total disability

$\wedge$ from 0 (lower) to 100 (higher) quality of life level

$*_{p}<0.05 ; * * p<0.01$ 
Table 4. MusiCare scores according to sociodemographics and clinical characteristics: patients and caregivers

\begin{tabular}{|c|c|c|c|c|c|c|c|c|c|c|c|}
\hline & & Patients & & & & & Caregivers & & & & \\
\hline & & $\begin{array}{l}\text { Inform. } \\
\text { about the } \\
\text { disease }^{\circ}\end{array}$ & $\begin{array}{l}\text { Inform. } \\
\text { Treatm./med. } \\
\text { Investigation }\end{array}$ & $\begin{array}{l}\text { Relationships } \\
\text { health care } \\
\text { teams }^{\circ}\end{array}$ & $\begin{array}{l}\text { Health } \\
\text { care } \\
\text { access }^{\circ}\end{array}$ & $\begin{array}{l}\text { Reception } \\
\text { conditions in } \\
\text { care centres }^{\circ}\end{array}$ & $\begin{array}{l}\text { Inform. } \\
\text { about the } \\
\text { disease }^{\circ}\end{array}$ & $\begin{array}{l}\text { Inform. } \\
\text { Treatm./med. } \\
\text { Investigation }\end{array}$ & $\begin{array}{l}\text { Relationships } \\
\text { health care } \\
\text { teams }^{\circ}\end{array}$ & $\begin{array}{l}\text { Health } \\
\text { care } \\
\text { access }^{\circ}\end{array}$ & $\begin{array}{l}\text { Reception } \\
\text { conditions in } \\
\text { care centres }\end{array}$ \\
\hline \multirow[t]{3}{*}{ Gender } & Women & $65,38 \pm 20,68$ & $77,46 \pm 19,20$ & $81,18 \pm 17,86$ & $59,27 \pm 18,06$ & $59,91 \pm 17,94$ & $63,12 \pm 20,99$ & $70,56 \pm 21,30$ & $77,17 \pm 18,41$ & $54,98 \pm 20,16$ & $56,83 \pm 18,34$ \\
\hline & Men & $67,19 \pm 19,61$ & $75,57 \pm 18,86$ & $78,99 \pm 17,43$ & $60,91 \pm 16,29$ & $62,31 \pm 16,40$ & $68,98 \pm 17,78$ & $75,28 \pm 16,31$ & $78,99 \pm 18,41$ & $58,99 \pm 15,94$ & $61,20 \pm 15,80$ \\
\hline & $\mathrm{p}$-value & 0,352 & 0,295 & 0,183 & 0,304 & 0,162 & 0,004 & 0,019 & 0,340 & 0,037 & 0,020 \\
\hline Age & $\mathrm{R}$ & 0,074 & 0,07 & 0,122 & 0,083 & 0,031 & 0,094 & 0,057 & 0,168 & 0,09 & $-0,071$ \\
\hline (years) & $p$-value & 0,082 & 0,095 & 0,003 & 0,050 & 0,484 & 0,077 & 0,285 & 0,001 & 0,093 & 0,207 \\
\hline \multirow[t]{3}{*}{ Marital status } & Couple & $67,40 \pm 19,85$ & $78,04 \pm 18,47$ & $81,33 \pm 17,65$ & $60,51 \pm 17,12$ & $60,38 \pm 16,57$ & $66,65 \pm 19,44$ & $73,82 \pm 18,43$ & $79,01 \pm 18,04$ & $57,40 \pm 17,81$ & $59,93 \pm 16,85$ \\
\hline & Single & $61,32 \pm 21,22$ & $73,14 \pm 20,80$ & $78,24 \pm 18,05$ & $56,37 \pm 18,80$ & $61,07 \pm 19,82$ & $62,47 \pm 22,18$ & $67,74 \pm 22,88$ & $71,13 \pm 20,59$ & $54,44 \pm 20,29$ & $52,38 \pm 18,60$ \\
\hline & $p$-value & 0,001 & 0,007 & 0,062 & 0,013 & 0,690 & 0,232 & 0,068 & 0,016 & 0,362 & 0,025 \\
\hline \multirow[t]{3}{*}{ Educ, level } & $<12$ years & $65,54 \pm 21,84$ & $75,06 \pm 20,84$ & $81,02 \pm 16,98$ & $62,77 \pm 17,25$ & $63,09 \pm 19,19$ & $67,49 \pm 18,91$ & $73,81 \pm 18,32$ & $79,31 \pm 17,29$ & $58,64 \pm 18,76$ & $59,06 \pm 19,50$ \\
\hline & $>=12$ years & $66,03 \pm 19,87$ & $77,56 \pm 18,40$ & $80,56 \pm 18,02$ & $58,72 \pm 17,37$ & $59,64 \pm 16,88$ & $65,70 \pm 19,59$ & $73,14 \pm 18,80$ & $77,53 \pm 18,94$ & $56,35 \pm 17,65$ & $59,46 \pm 15,69$ \\
\hline & $\mathrm{p}$-value & 0,799 & 0,165 & 0,779 & 0,014 & 0,047 & 0,402 & 0,746 & 0,376 & 0,253 & 0,841 \\
\hline \multirow[t]{3}{*}{ MS subtype } & $\begin{array}{l}\text { Relaps, } \\
\text { remitting }\end{array}$ & $66,74 \pm 20,44$ & $77,93 \pm 19,14$ & $81,24 \pm 17,39$ & $59,25 \pm 17,96$ & $59,58 \pm 18,43$ & $66,78 \pm 18,44$ & $74,53 \pm 17,87$ & $77,82 \pm 18,04$ & $57,95 \pm 16,47$ & $60,23 \pm 17,14$ \\
\hline & Progressive & $64,70 \pm 20,74$ & $75,57 \pm 19,58$ & $80,21 \pm 17,92$ & $61,89 \pm 15,01$ & $61,14 \pm 16,09$ & $65,68 \pm 19,93$ & $71,91 \pm 19,69$ & $78,81 \pm 18,05$ & $56,08 \pm 18,19$ & $58,12 \pm 16,40$ \\
\hline & $p$-value & 0,291 & 0,185 & 0,519 & 0,075 & 0,354 & 0,595 & 0,199 & 0,606 & 0,319 & 0,267 \\
\hline $\begin{array}{l}\text { Disease } \\
\text { duration }\end{array}$ & $\mathrm{R}$ & 0,049 & 0,030 & 0,058 & $-0,008$ & $-0,060$ & $0,175^{* *}$ & 0,063 & $0,175^{* *}$ & 0,009 & $-0,008$ \\
\hline (years) & $\mathrm{p}$-value & 0,267 & 0,485 & 0,175 & 0,860 & 0,188 & 0,001 & 0,254 & 0,001 & 0,872 & 0,896 \\
\hline \multirow[t]{3}{*}{ MS treatment } & No & $63,44 \pm 22,84$ & $73,14 \pm 19,99$ & $80,17 \pm 16,11$ & $58,42 \pm 19,03$ & $58,83 \pm 18,42$ & & & & & \\
\hline & Yes & $66,49 \pm 19,75$ & $77,72 \pm 18,89$ & $80,83 \pm 18,15$ & $59,84 \pm 17,43$ & $60,99 \pm 17,31$ & & & & & \\
\hline & $p$-value & 0,159 & 0,022 & 0,711 & 0,439 & 0,251 & & & & & \\
\hline
\end{tabular}




\begin{tabular}{|c|c|c|c|c|c|c|}
\hline Relationship & Love partner & $67,38 \pm 19,13$ & $74,43 \pm 17,93$ & $79,37 \pm 17,75$ & $57,91 \pm 17,51$ & $60,92 \pm 15,96$ \\
\hline \multirow[t]{2}{*}{ with MS patient } & Other* & $61,89 \pm 21,29$ & $68,36 \pm 21,60$ & $73,80 \pm 20,31$ & $54,55 \pm 19,62$ & $52,77 \pm 19,88$ \\
\hline & $p$-value & 0,026 & 0,010 & 0,017 & 0,140 & $<0,001$ \\
\hline Presence of & No & $64,70 \pm 19,82$ & $70,21 \pm 21,03$ & $75,59 \pm 19,10$ & $52,92 \pm 21,09$ & $55,72 \pm 19,93$ \\
\hline \multirow[t]{2}{*}{ other caregiver } & Yes & $66,90 \pm 19,87$ & $74,46 \pm 18,09$ & $79,27 \pm 18,24$ & $59,18 \pm 16,28$ & $61,23 \pm 15,10$ \\
\hline & $p$-value & 0,332 & 0,049 & 0,081 & 0,006 & 0,016 \\
\hline
\end{tabular}

$\mathrm{R}$, correlation coefficient; $M S$, multiple sclerosis

Bold values: $p$-value $<0,05$ 
Table 5. Reproducibility and responsiveness of MusiCare

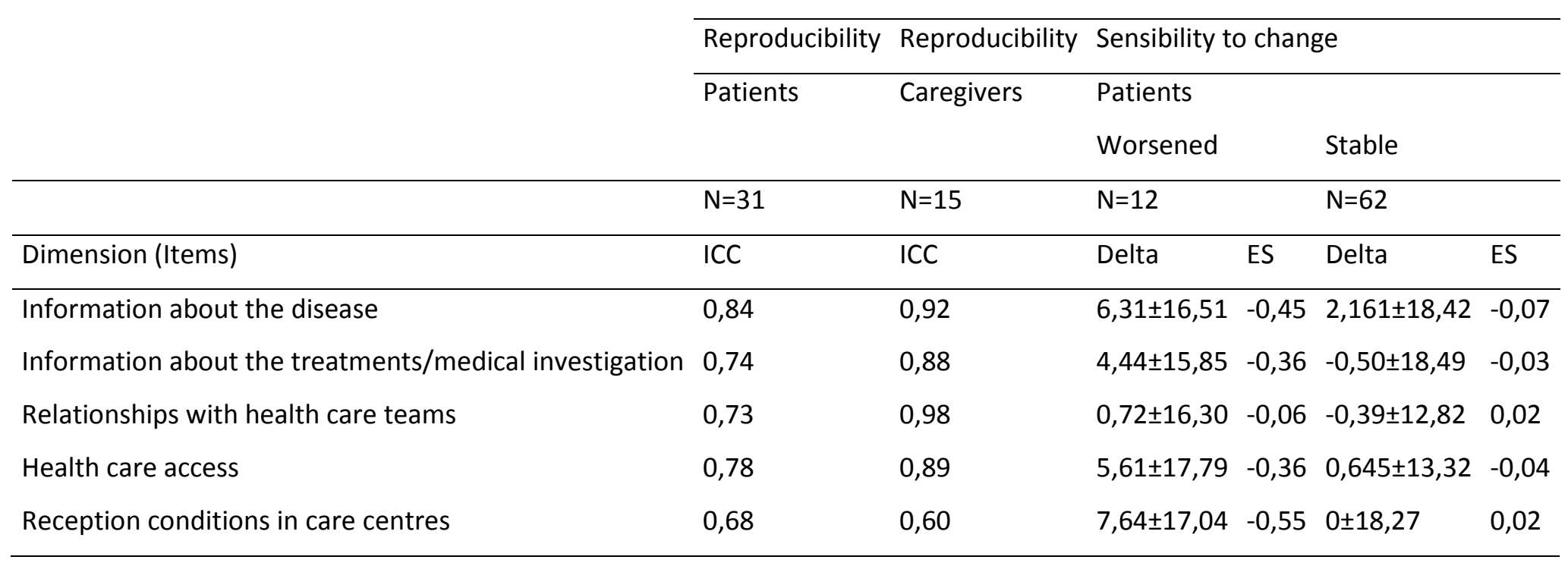

ICC, intraclass correlation coefficients ; Delta, delta change between baseline assessment and \$\$-month assessment ; ES, effect size (final score - initial score)/initial score (|0,2| small, |0,5| moderate, and $|0,8|$ large change [Algina J, Keselman HJ, Penfield RD: Effect Sizes and their Intervals: The Two-Level Repeated Measures Case, Educational and Psychological Measurement $2005,65(2): 241-258])$, 
Figure 1. MusiCare scores for patients and caregivers

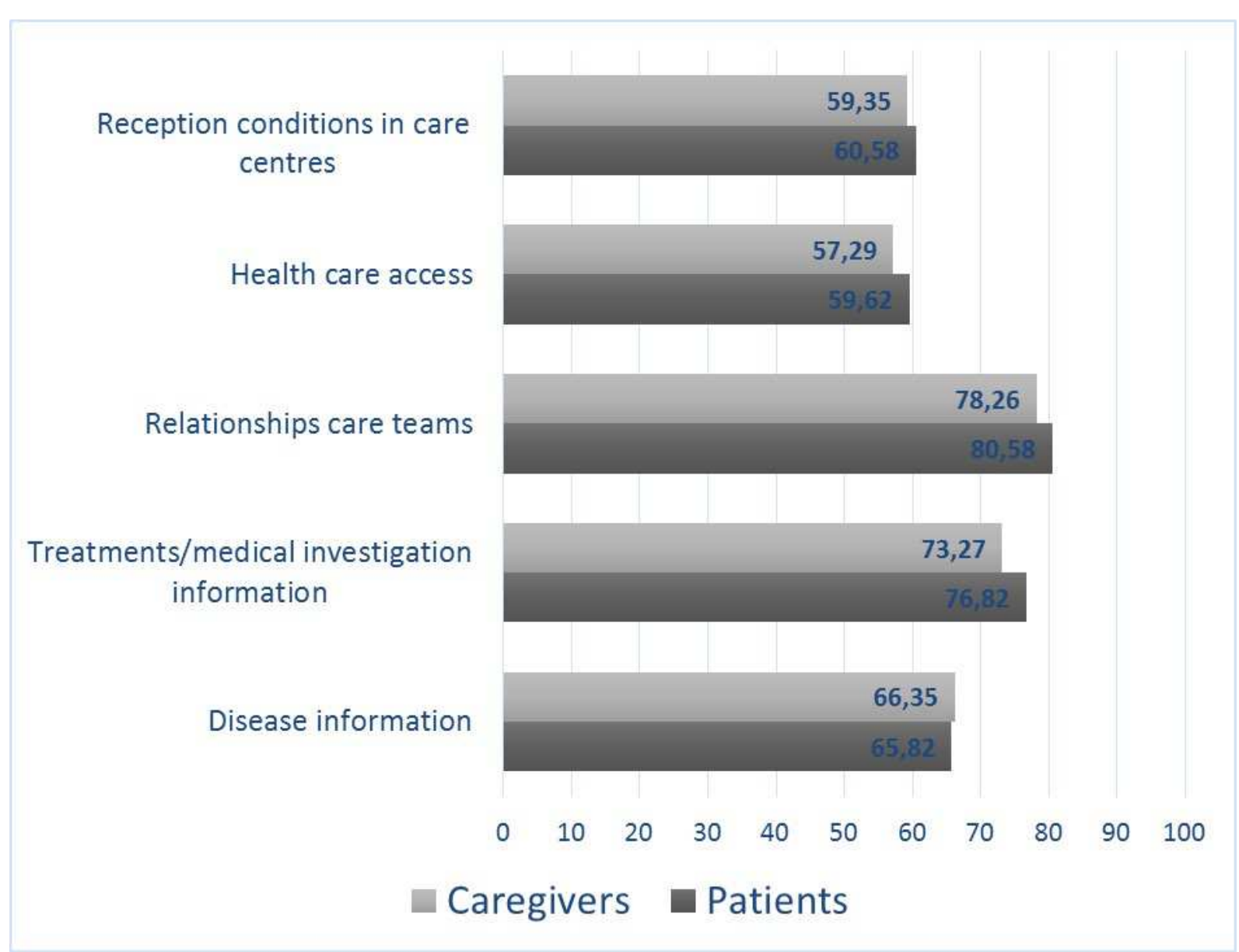

